\title{
REPEATED STRESS ALTERS DENDRITIC SPINE MORPHOLOGY IN THE RAT MEDIAL PREFRONTAL CORTEX
}

\author{
Jason J. Radley ${ }^{*}, 1$, Anne B. Rocher ${ }^{2,3}$, Alfredo Rodriguez $2,3,4$, Douglas B. \\ Ehlenberger $2,3,4$, Mark Dammann ${ }^{1}$, Bruce S. McEwen ${ }^{5,6}$, John H. Morrison ${ }^{2,6}$, Susan L. \\ Wearne $^{2,3,4}$, and Patrick R. Hof ${ }^{\star}, 2,3,6$ \\ ${ }^{1}$ Laboratory of Neuronal Structure and Function, Salk Institute for Biological Studies, La Jolla, CA \\ 92037, USA \\ ${ }^{2}$ Department of Neuroscience, Mount Sinai School of Medicine, New York, NY 10029, USA \\ ${ }^{3}$ Computational Neurobiology Imaging Center, Mount Sinai School of Medicine, New York, NY \\ 10029, USA \\ ${ }^{4}$ Center for Biomathematical Science, Mount Sinai School of Medicine, New York, NY 10029, USA \\ ${ }^{5}$ Laboratory of Neuroendocrinology, Rockefeller University, New York, NY 10021, USA \\ ${ }^{6}$ Center for the Neurobiology of Fear and Anxiety, New York University, New York, NY 10003, USA
}

\begin{abstract}
Anatomical alterations in the medial prefrontal cortex (mPFC) are associated with hypothalamopituitary adrenal (HPA) axis dysregulation, altered stress hormone levels, and psychiatric symptoms of stress-related mental illnesses. Functional imaging studies reveal impairment and shrinkage of the $\mathrm{mPFC}$ in such conditions, and these findings are paralleled by experimental studies showing dendritic retraction and spine loss following repeated stress in rodents. Here we extend this characterization to how repeated stress affects dendritic spine morphology in mPFC through the utilization of an automated approach which rapidly digitizes, reconstructs 3-dimensionally, and calculates geometric features of neurons. Rats were perfused after being subjected to 3 weeks of daily restraint stress (6 hours/day), and intracellular injections of Lucifer Yellow were made in layers II/III pyramidal neurons in the dorsal mPFC. To reveal spines in all angles of orientation, deconvolved high-resolution confocal laser scanning microscopy image stacks of dendritic segments were reconstructed and analyzed for spine volume, surface area, and length using a Rayburst-based automated approach $(8,091$ and 8,987 spines for control and stress, respectively). We found that repeated stress results in an overall decrease in mean dendritic spine volume and surface area, which was most pronounced in the distal portion of apical dendritic fields. Moreover, we observed an overall shift in the population of spines, manifested by a reduction in large spines and increase in small spines. These results suggest a failure of spines to mature and stabilize following repeated stress, and are likely to have major repercussions on function, receptor expression, and synaptic efficacy.
\end{abstract}

\section{Indexing terms}

dendritic spine; morphometry; plasticity; prefrontal cortex; stress

*Correspondence to: Jason J. Radley, Laboratory of Neuronal Structure and Function, Salk Institute for Biological Studies, La Jolla, CA, 92037, USA. radley@ salk.edu, or Patrick R. Hof, Department of Neuroscience, Mount Sinai School of Medicine, Box 1065, One Gustave L. Levy Place, New York, NY 10029.

Associate editor: Jeffrey H. Kordower 


\section{INTRODUCTION}

Life stress has been demonstrated to play a critical role in the etiology of numerous psychiatric illnesses, such as depression, post-traumatic stress disorder, anxiety (Sapolsky, 1996; Heim et al., 1997; McEwen, 1998; Newport and Nemeroff, 2000; Caspi et al., 2003), and in other instances it may precipitate the onset of psychotic disorders (Corcoran et al., 2001; Phillips et al., 2007). Functional imaging studies in humans suggest that medial prefrontal cortex (mPFC) dysfunction is correlated with abnormalities in neuroendocrine regulation as well as with cognitive and affective changes that are symptomatic in many stress-related mental illnesses (Newport and Nemeroff, 2000; Shin et al., 2001; Shin et al., 2004). Rodent models have provided much information about prefrontal cortical function and its role in emotional stress regulation. One overarching principle that has emerged from this research is that the $\mathrm{mPFC}$ has the capacity to modulate the stress-responsive hypothalamo-pituitary-adrenal (HPA) axis (Diorio et al., 1993; Figueiredo et al., 2003; Radley et al., 2006a), yet is also a target of the effects of repeated stress (Cook and Wellman, 2004; Radley et al., 2004; Radley et al., 2006b; Murmu et al., 2006; Cerqueira et al., 2007). Detailed investigation of how repeated stress affects neuronal morphology in the mPFC may provide a cellular and synaptic basis for the neuroendocrine and behavioral manifestations of stress, particularly with respect to longlasting pathology. Several reports have shown that repeated stress induces the retraction and debranching of apical, but not basal, dendrites in mPFC pyramidal neurons (Cook and Wellman, 2004; Radley et al., 2004; Radley et al., 2005; Brown et al., 2005; Liston et al., 2006). In addition, repeated stress also reduces apical dendritic spine density in the mPFC (Radley et al., 2006b).

In recent years, much progress has been made in understanding the relationship between dendritic spine structure and function. Dendritic spines are highly motile structures that have the capacity to undergo rapid changes in response to physiological and environmental stimuli (Woolley and McEwen, 1994; Kirov et al., 2004; Yuste and Bonhoeffer, 2004; Zhang et al., 2005). In this regard, the shape of dendritic spines has been shown to provide for biochemical compartmentalization that is critical for regulating synaptic plasticity (for review see Nimchinsky et al., 2002). Repeated stress-induced dendritic retraction in the $\mathrm{mPFC}$ has recently been shown to correlate with functional deficits in attentional control (Liston et al., 2006). Thus, an analysis of how chronic stress modifies dendritic spine morphology may help in elucidating the cellular mechanisms that give rise to such mPFC-dependent behavioral alterations.

Recently, we developed a novel algorithm, Rayburst sampling, for automated threedimensional shape analysis from laser scanning microscopy images (Rodriguez et al., 2006). Rayburst defines and casts a multidirectional core of rays from an interior point to the surface of a solid, allowing precise quantification of anisotropic and irregularly shaped 3D structures. The development of this Rayburst-based approach has allowed for the implementation of very high resolution three-dimensional (3D) morphometric analyses of dendritic spines on mPFC pyramidal neurons, that permits rapid and automated digitizing, 3D reconstruction, and geometric analyses on deconvolved optical stacks of dendritic segments (Wearne et al., 2005; Rodriguez et al., 2006). In this study, we utilized the Rayburst-based automated approach to examine the effect of repeated restraint stress on dendritic spine morphology in Lucifer Yellow-filled pyramidal neurons in layers II/III of the rat mPFC. Part of this work has been previously reported in abstract form (Radley et al., 2006c). 


\section{METHODS}

\section{Animals and treatments}

Adult male Sprague-Dawley albino rats (300-350 g by the first day of the experimental treatments) were group housed in a temperature-controlled room on a 12 hour light/dark cycle with the light period beginning at 7:00 A.M. Food and water were available ad libitum. Rats were adapted to handling for 7 days before any manipulations were performed. All procedures were conducted in accordance with the National Institutes of Health Guide for the Care and Use of Laboratory Animals and were approved by the Rockefeller University and Mount Sinai School of Medicine Institutional Animal Care and Use Committees.

Rats were placed in wire mesh restrainers for 6 hours starting at 10:00 A.M. Stress exposure was timed to occur in the middle of the lights-on phase of the diurnal cycle. The restraint stress procedure was performed daily for 21 days. After the last day of the repeated stress procedure, rats were anesthetized with chloral hydrate $(350 \mathrm{mg} / \mathrm{kg}$, i.p.) and perfused via the ascending aorta at a rate of $55 \mathrm{ml} / \mathrm{min}$ with $100 \mathrm{ml}$ of ice-cold $1 \%$ paraformaldehyde in $0.1 \mathrm{M}$ phosphatebuffered saline (PBS; pH 7.4), followed by fixation with $4 \%$ paraformaldehyde with $0.125 \%$ glutaraldehyde in $0.1 \mathrm{M}$ PBS. The brains were removed and postfixed for 2 hours in the same fixative.

\section{Intracellular dye injections}

Serial $250 \mu \mathrm{m}$-thick coronal sections were collected from the frontal pole using a Vibratome and stored in $0.1 \mathrm{M}$ PBS. Sections were briefly immersed in a fluorescent nucleic acid stain (4,6-diamidino-2-phenylindole; Sigma, St. Louis, MO) to display the cytoarchitectonic features of the prefrontal cortical subfields of interest for intracellular filling. Sections were mounted on nitrocellulose filter paper and submerged in a tissue culture dish containing $0.1 \mathrm{M}$ PBS, and viewed under fluorescence using a fixed-stage microscope. Intracellular fluorescent dye filling was carried out by microinjecting layers II/III pyramidal neurons in the dorsal mPFC with 5\% Lucifer Yellow (Molecular Probes, Eugene, OR). Injections were made by iontophoresis through micropipettes (1-2 $\mu \mathrm{m}$ inner diameter) under a DC current of 1-6 nA for 10 minutes. The sections were then mounted onto glass slides and coverslipped in PermaFluor.

\section{Neuronal and dendritic reconstructions}

To ensure that the neuronal reconstructions and data analyses were performed by an experimenter unaware of the treatment condition, each animal was coded by an independent observer, and the code was not broken until all analyses were completed. The selection method for dendritic segmental spine morphologic analysis was designed to minimize any possible bias. Initially, pyramidal neuron dendritic arbors were reconstructed in 3D using a computerassisted morphometry system consisting of a Zeiss (Thornwood, NY) Axioplan 2

photomicroscope equipped with an Applied Scientific Instrumentation (Eugene, OR) MS-2000 XYZ computer-controlled motorized stage, a DAGE-MTI DC-330 video camera, a Gateway computer, and morphometry software (MBF Biosciences, Williston, VT). Neurons were visualized, and the dendritic tree was reconstructed using a Zeiss Apochromat 40X objective with a numerical aperture (N.A.) of 1.4 and Neurolucida software (MBF Biosciences). Neurons had to exhibit complete filling of the dendritic tree, as evidenced by well-defined endings, and display intact primary, secondary, and tertiary branches in order to be considered for further analysis.

Two-dimensional dendritic tracing diagrams that were rendered for each neuron from Neurolucida (MBF Biosciences) were printed and concentric circles were drawn at radial increments of $75 \mu \mathrm{m}$ relative to the soma (Fig. 1). Dendritic branches falling within the domains 
bounded by these concentric circles (i.e., $<75 \mu \mathrm{m}, 75-150 \mu \mathrm{m},>150 \mu \mathrm{m}$ ) were randomly selected for visualization on the confocal laser-scanning microscope (CLSM; Zeiss LSM 410, Oberkochen, Germany). Lucifer Yellow was excited by an $\mathrm{Ar} / \mathrm{Kr}$ laser at $488 \mathrm{~nm}$ (attenuation set at 10). Settings for pinhole size, aperture, gain, and offset were optimized initially and then held constant throughout the study to ensure that all images were digitized under the same illumination conditions at a resolution of $256 \times 256$ pixels. Strict criteria for dendritic segment selection were used prior to reconstruction on the CLSM: (1) each had to reside within a depth of $50 \mu \mathrm{m}$ from the top surface of the section, due to the limited working distance of the optical system; (2) each had to be either parallel to, or at acute angles relative to the coronal surface of the section; and (3) there was no overlap with other branches that would obscure visualization of spines. Each designated segment $(25-50 \mu \mathrm{m}$ in length) that met these criteria was located in the microscope field, and confocal stacks of 100-250 digital images separated by a $z$-step of $0.1 \mu \mathrm{m}$ were captured using a Zeiss Plan-Apochromat 100X (1.4 N.A.) oil-immersion objective on the CLSM. All confocal stacks included at least $1 \mu \mathrm{m}$ above and below the identified dendritic segment. An average of 4 high-resolution $z$-stacks were captured per neuron (a total of 50 neurons were used for spine analysis: 25 from control and 25 from repeatedly restrained animals, $\mathrm{N}=5$ animals per group). The confocal stacks were deconvolved with AutoDeblur (version 8.0.2.; Autoquant, Troy, NY). For data presentation, composites from deconvolved optical stacks were exported first to Adobe Photoshop (version 7; Adobe Systems, San Jose, CA) for adjustments to optimize/balance contrast and brightness and then to Canvas (version 8; Deneba Systems, Miami, FL) for assembly and labeling.

The Rayburst-based automated system digitizes, reconstructs in three dimensions, and performs geometric analyses on deconvolved confocal stacks of dendritic segments in two principal steps (Fig. 2; Wearne et al., 2005;Rodriguez et al., 2006). First, the medial axis of the dendritic segment is extracted using a dynamically adjusting local segmentation technique. Next, voxels in the vicinity of the medial axis are clustered into spines by building layers from local high points toward the dendrite surface. A 3D Rayburst Sampling algorithm run from the center of mass of each spine cluster extracts spine geometric features, returning volume and surface area for spines oriented at any angle with respect to the dendrite (Rodriguez et al., 2006). The open-source code for implementing the algorithm is freely available for download from the Computational Neurobiology and Imaging Center, Mount Sinai School of Medicine, website http://www.mssm.edu/cnic/tools.html (Wearne and Hof). It is also available from the Journal of Comparative Neurology website as an on-line supplement. The program is implemented in ANSI C and as such is platform-independent. It will run on any computer once it is compiled with any compliant $\mathrm{C}$ compiler (see ReadMe file in supplement). Additional details and performance tests on specific machines were previously reported (Rodriguez et al., 2006)

\section{Statistics}

Values from each morphometric parameter (spine volume, spine surface area, spine length) on each dendritic segment were averaged, and then averaged for each animal, and values per animal were used for the comparison of means. Each treatment (Control and $21 \mathrm{~d}$ Stress) consisted of 5 animals, with 5 Lucifer Yellow-filled neurons analyzed from each animal, and 4 dendritic segments analyzed for a given neuron. The normality of the population of dendritic segments was examined with the Kolmogorov-Smirnov test. Given that the distributions for each morphometric parameter analyzed were Gaussian, the group means were compared with a mixed design ANOVA with one within-(apical: $<75 \mu \mathrm{m}, 75-150 \mu \mathrm{m},>150 \mu \mathrm{m}$; basal: $<75$ $\mu \mathrm{m}, 75-150 \mu \mathrm{m}$ ) and one between- (control, stress) group variable, followed by post hoc pairwise comparisons using Bonferroni's correction. In addition, to determine whether changes in spine dimensions occurred equally across the entire spectrum of size measurements or are more pronounced in specific subpopulations of spines (e.g., the smallest and largest), all spine 
parameters from both groups were pooled and the 25th and the 75th percentiles for each parameter were determined. Then, for a given size parameter, the differences in proportions of spines below the 25 th percentile, as well as above the 75 th percentile, were examined between groups. The $\chi^{2}$-test was used to compare the proportions below the first quartile cutoffs between the groups, as well as the proportions above the third quartile cutoffs (Knafo et al., 2005). Grouped data were expressed as the mean + SEM based on one aggregate, or average, per animal.

\section{RESULTS}

Previous reports have shown that the repeated restraint procedure (6 hours/day, 21 days) used in the present study activates the stress-responsive HPA axis, and produces modest, but significant increases in adrenal weights compared with unstressed rats (Watanabe et al., 1992; Magariños and McEwen, 1995). Although we did not assess either of these indices of stress activation, we did verify that 21 days of repeated daily restraint stress resulted in a15\% reduction in body weight compared to unstressed controls $(P<0.005$; see Watanabe et al., 1992).

The precise location of Lucifer Yellow-filled pyramidal neurons in layers II/III of the dorsal mPFC was evaluated with reference to standard cytoarchitectonic parcellations of the region (Krettek and Price, 1977; Vogt and Peters, 1981). The two fields of primary interest are the dorsal subdivision of the anterior cingulate area (ACd), and prelimbic area (PL). Using the fluorescent nucleic acid counterstain (4,6-diamidino-2-phenylindole), the ACd is characterized by a sparse layer II and a broad layer V, distinguishing it from PL, which contains a more homogeneous layer $\mathrm{V}$ comprised of larger nuclei. Layer I is nearly devoid of neurons, in contrast to the cell-dense layers II/III, permitting clear establishment of laminar borders. Figure 3 provides an example of the locations for each of the Lucifer Yellow-filled pyramidal neurons in the dorsal mPFC that were subject to the dendritic tracing and spine morphometric analysis.

In a previous report repeated stress was shown to induce spine loss in apical dendrites of dorsal mPFC pyramidal neurons (Radley et al., 2006b). While this earlier study reported spine density estimates from confocal stacks of three-dimensionally reconstructed dendritic segments (25$50 \mu \mathrm{m}$ in length), spine densities were manually determined by counting the number of spines for each length of dendritic segment and expressing values in terms of spines $/ \mu \mathrm{m}$. Changes in mean spine density as a function of treatment status were readily determined from the Rayburstbased automated system, as an initial step in the algorithm involves the extraction of the medial axis of the dendritic segment and recognition of spines using a dynamically adjusting local segmentation technique. Fifty branches from the data set were randomly subjected to counting using both manual and Rayburst-based automated approaches. The Rayburst-based automated spine analysis system yielded spine densities that were $87 \%$ similar to the manual counting approach.

Repeated restraint stress produced an overall $11 \%$ decrease in spine density throughout apical and basal dendrites of dorsal mPFC pyramidal neurons in layers II/III $\left(F_{(1,8)}=8.3 ; P<0.05\right.$; Fig. 4, upper left) and an overall $12 \%$ decrease in apical dendritic spine density $(P<0.05$; Fig. 4 , middle left). There was also a main effect for dendritic spine density relative to distance from the soma $\left(F_{(4,8)}=10.1 ; P<0.005\right)$, and no interaction between experimental treatment and distance from the soma $\left(F_{(4,8)}=1.6 ; P=0.2\right)$. By location on the apical dendritic arbor, the stress-induced reduction in spine density was most pronounced at $>150 \mu \mathrm{m}$ relative to the soma (15\% decrease, $P<0.05$; Fig. 4 , middle left). Although stress did not have any significant overall effect on basal dendritic spine density, a $13 \%$ decrease in spine density was present at radial distances of $<75 \mu \mathrm{m}(P<0.05$; Fig. 4, lower left $)$. 
The dendritic spine morphometric parameters of volume, surface area, and length were assessed for each dendritic spine using the Rayburst-based automated approach. A total of 187 dendritic segments were analyzed (92 control, 97 repeated stress), and 17,078 dendritic spines (8,091 control, 8,987 repeated stress). Based on 5 animals/group, and 5 neurons/animal, a mean of 3.7 and 3.9 dendritic segments/neuron were analyzed for the control and repeated stress groups, respectively. In unstressed controls, an average of 12 apical and 6.4 basal dendritic segments were analyzed per animal (totaling 5,383 and 2,708 spines, respectively), and in the repeatedly stressed group, an average of 12.4 apical and 7 basal dendritic segments were analyzed per animal (totaling 5,587 and 3,400 spines, respectively).

Repeated restraint stress resulted in an overall $10 \%$ decrease in mean dendritic spine volume $\left(F_{(1,8)}=7.3 ; P<0.05 ;\right.$ Fig. 5$)$ and surface area $\left(F_{(1,8)}=15.3 ; P<0.005\right.$; Fig. 6$)$, and no effect on spine length $\left(F_{(4,8)}=2.2 ; P=0.2 ;\right.$ Fig. 7$)$, in pyramidal neurons in layers II/III of the dorsal $\mathrm{mPFC}$. Regarding mean spine volume, there was also a main effect for distance from the soma $\left(F_{(4,8)}=3.9 ; P<0.05\right)$, and no interaction $\left(F_{(4,8)}=0.6 ; P=0.6\right)$, whereas no effects for distance $\left(F_{(4,8)}=1.3 ; P=0.3\right)$ or interaction $\left(F_{(4,8)}=0.6 ; P=0.7\right)$ were evident for mean spine surface area.

Similar to the effects of stress on dendritic spine density, the reduction in mean spine volume and surface area is most prominent in the more distal aspect $(>150 \mu \mathrm{m})$ of apical dendrites (10\% decrease, $P<0.05$; Fig. 5, Fig. 6). Moreover, basal dendrites show a significant reduction in mean spine volume and surface area, focused in the proximal aspect $(<75 \mu \mathrm{m})$ following repeated stress (Fig. 5, Fig. 6). While 21 days of repeated restraint stress did not significantly affect overall mean spine length $\left(F_{(1,8)}=2.3 ; P=0.2\right)$, there was a main effect for distance from the soma $\left(F_{4,8}=4.9 ; P<0.05\right)$, and no interaction between treatment and distance $\left(F_{(4,8)}=1.1 ; P=0.4\right)$. Repeated stress produced a smaller, albeit significant decrease in spine length ( $6 \%$ decrease), which was once again focused in apical dendrites at radial distances $>150 \mu \mathrm{m}$ (Fig. 7).

To determine whether there was an overall shift in the spine size distribution following repeated stress, or a disproportionate change in the incidence of spines of smaller volume, surface area, and length, the frequency of spines in the top and bottom quartile for the subject population as a whole (i.e., control and repeated stress groups) were analyzed. For volume and surface area, the proportions of spines on apical and basal dendrites following repeated stress were higher in the lowest quartile, and lower in the highest quartile, relative to unstressed controls $(P<$ 0.001; Table 1). While a similar shift in spine length distribution was also present, the effect was limited to apical dendrites $(P<0.001$; Table 1$)$. Spines on apical dendritic segments at radial distances $>150 \mu \mathrm{m}$ from soma exhibited the most pronounced shift in frequency distribution in all three dimensions examined (Table 1, Fig. 8).

\section{DISCUSSION}

These results show that dendritic spine morphology in $\mathrm{mPFC}$ pyramidal neurons is altered in response to repeated restraint stress. This analysis was made possible using a Rayburst-based automated spine analysis system (Wearne et al., 2005; Rodriguez et al., 2006), which affords the rapid and automated calculation of spine morphometric parameters in 3D. Mean values for spine volume and surface area underwent an $11 \%$ reduction on apical and basal dendritic arbors in pyramidal neurons following repeated stress. Such decreases in spine size are likely to have major repercussions on function, receptor expression, and efficacy. The more distal aspect of apical dendritic arbors exhibited the most pronounced decreases in all three dendritic spine morphometric parameters (volume, surface area, length). This region also revealed significant shifts in the frequency distribution of spines, such that there were significantly fewer spines 
represented in the upper quartile which suggests a selective failure of spine synapses to either mature or stabilize.

One important aspect to this study is that it underscores the advantage of employing automated, 3D spine analysis methods over more traditional approaches for the analysis of spine morphometric parameters. Previously, we and others have calculated spine morphometric features manually, by measuring spine head/neck length and diameters, and calculating spine head volume based upon the assumption that spine heads are ellipsoidal (Knafo et al., 2005;

Hao et al., 2006). Whereas this method may be employed in fluorescent dye-labeled or Golgiimpregnated neurons, measurements are limited to spines that are parallel to the plane of section, excluding spines that are oriented at oblique angles or obscured by residual glow immediately above or below the dendritic segment. Furthermore, this approach limits the ability to characterize spines of different morphologic classes, such as long filopodial-type or short stubby spines. The Rayburst-based automated approach performs high-resolution analyses on deconvolved optical stacks of dendritic segments obtained from the confocal laserscanning microscope, allowing for each spine to be completely reconstructed in $3 \mathrm{D}$, regardless of the plane of orientation, morphologic classification, or position relative to the dendritic segment. Finally, automated morphometric analyses can be performed very rapidly (i.e., 2-3 seconds) for a given dendritic segment (i.e., 80-100 spines), yielding spine volume, surface area, and length for each spine almost instantaneously, while manual approaches of measurement and calculation of spine head volume for the same segment may take several hours (Radley, Hof, Wearne, unpublished observations). One limitation of characterizing spine morphometric features at the light- and confocal microscopic level is that it is not possible to visualize synapses made onto dendritic shafts or cell bodies. Whereas electron microscopic (EM) serial section reconstruction of synapses remains the highest standard for the morphologic characterization for spines and synapses, reconstruction of sufficiently large datasets for robust statistical analysis at the EM level remains infeasible with the current technology.

Previous work from our group has shown that repeated stress induces apical dendritic retraction and spine loss in layers II/III mPFC pyramidal neurons (Radley et al., 2004; Radley et al., 2005; Radley et al., 2006b; Liston et al., 2006). Other groups that have examined the effects of repeated stress (Cook and Wellman, 2004; Brown et al., 2005) and corticosteroids (Wellman, 2001; Cerqueira et al., 2006) on dendritic morphology in layers II/III pyramidal neurons in $\mathrm{mPFC}$ have also observed similar alterations in dendritic length and branch number, particularly in distal apical dendrites. These effects are not likely to be limited to layers II/III pyramidal neurons, but are apt to be generalized to the entire pyramidal neuron population in mPFC. Liu and Aghajanian (2006) recently showed that repeated stress decreased apical dendritic branching and spine density in layer $\mathrm{V}$ pyramidal neurons in $\mathrm{mPFC}$, particularly in the more distal aspect of apical dendrites. Repeated stress and prolonged corticosteroid administration both result in a decrease in the volume of layer I in the dorsal mPFC (Cerqueira et al., 2005; Cerqueira et al., 2007), the region containing apical dendrites from both pyramidal cell populations in layers II/III and V. In support of the present findings, in nearly all of the aforementioned studies, the effects of repeated stress on structural plasticity were most prominent in distal apical dendrites. Collectively, these studies suggest that distal apical dendrites are most sensitive to the effects of repeated stress, resulting in a significant decrease in the population of excitatory synapses in distal apical dendrites residing in superficial layer I near the pial surface. It is important to note that chronic stress-induced plasticity in mPFC is not considered to be part of a pathological sequels leading to neurotoxicity, since repeated stress has not been found to result in a decrease in cell number or volume in pyramidal layers II/III or V in mPFC (Cerqueira et al., 2007), and that these morphologic changes are reversible following a stress-free recovery period (Radley et al., 2005). 
One interesting difference that we observed in the present study was that spine densities in proximal basal dendrites ( $<75 \mu \mathrm{m}$ from the soma) were reduced following repeated stress, while in a previous report significant reductions in spine densities were limited to apical dendrites (Radley et al., 2006b). One possibility is that refinements in the experimental design may account for such a difference, e.g., sampling of the dendritic arbor at $75 \mu \mathrm{m}$ versus $50 \mu \mathrm{m}$ radial distances from the soma in the present and previous report, respectively. A more likely possibility is that the manual counting methods used for determining spine densities in Radley et al. (2006b) produced a larger variance than that which resulted from the Rayburst-based automated analysis. In this regard, we found that the Rayburst-based automated approach yielded spine density values that were an $87 \%$ match to the manual counting approach. Although it is tempting to state that the automated approach is $87 \%$ "accurate" as compared to the manual counting approach, another explanation is that the manual counting is more subjective. Whereas an individual can reproduce spine density values from a given dendritic segment with virtually $100 \%$ accuracy, considerable variation (up to $35 \%$ in some instances) in spine density reporting has been noted among observers (Hof and Wearne, unpublished observations).

The reductions in spine volume and surface area, and a shift in spine size such that large spines became less prevalent following repeated stress, allows us to consider the decreases in spine density in the context of spine stability and plasticity. Larger spines have been shown to be more stable and less motile (Trachtenberg et al., 2002; Kasai et al., 2003; Holtmaat et al., 2005), and as a result, less plastic than smaller spines (Grutzendler et al., 2002). Spine size is also correlated with synapse size (Harris and Stevens, 1989), and larger postsynaptic densities have more $\alpha$-amino-3-hydroxy-5-methyl-4-isoxazole propionate (AMPA) receptors (Nusser et al., 1998; Kharazia and Weinberg, 1999; Takumi et al., 1999), consistent with the relative stability attributed to larger spines (Kasai et al., 2003). In contrast, $N$-methyl-D-aspartate (NMDA) receptors are more prevalent in small spines (Kasai et al., 2003), and are more sensitive to $\mathrm{Ca}^{2+}$-mediated signaling than large spines (Nimchinsky et al., 2004). Spine size is also related to the distribution of endocytic proteins, with such proteins closer to the synaptic edge in small spines (Racz et al., 2004), which might facilitate receptor insertion or promote changes in synaptic membrane structure in activated synapses. Whereas it is difficult to ascertain the functional consequences of the observed decrease in spine size and smaller proportion of large spines following repeated stress, when considered with spine loss, these morphologic changes are suggestive of a failure of spines to mature and stabilize.

In the context of plasticity, Kasai et al. (2003) have proposed that small spines represent "learning spines" that can either retract or become stabilized in the context of learning. By this view large spines are "memory spines" that are stabilized and retain information over the long term. Based on this information alone, it would appear that our analysis reveals that stress increases the proportion of small spines, a subset of which could be poised for an increase in size and stability and consolidation in the context of learning (Matsuzaki et al., 2004). However, because we found that stress also reduces the number of large spines and overall spine number, it seems more plausible that repeated stress may limit spine lability that would, in turn, result in the stabilization and retention of more mature morphologies, such as might be important for memory formation (Matsuzaki et al., 2004). We and others have shown that repeated stress produces mPFC-dependent learning impairments (Liston et al., 2006; Cerqueira et al., 2007). This suggests that repeated stress may impair mPFC-dependent learning through an inability of spines to undergo plasticity-induced shifts from the smaller "learning" to larger "memory" phenotypes. Holmes and colleagues have shown that shorter intervals of stress are also capable of impairing the extinction of fear conditioning, a form of learning that is also dependent on the mPFC (Izquierdo et al., 2006). While none of these studies have correlated learning with spine morphology in mPFC following stress, both acute and repeated stress-induced mPFCdependent learning impairments corresponded with decreased apical dendritic arborization in 
pyramidal neurons in this region (Izquierdo et al., 2006; Liston et al., 2006). Indeed, one interesting possibility is that short-term and repeated stress impact mPFC-dependent learning through differential effects on spine number and morphology.

\section{Supplementary Material}

Refer to Web version on PubMed Central for supplementary material.

\section{Acknowledgments}

We thank W.G.M. Janssen and K. Kelliher for expert technical assistance, J. Hao and W. Lou for help with the statistical analysis, and D.L. Dickstein for help with software development.

Grant Sponsor: NIH; Grant numbers: MH58911 (BSM, JHM, PRH), MH60734 (SLW), DC05669 (SLW), and RR16754 (SLW, PRH). Grant Sponsor: Anxiety Disorders Association of America Young Investigator Award (JJR), NARSAD Young Investigator Award (JJR).

\section{REFERENCES}

Brown SM, Henning S, Wellman CL. Mild, short-term stress alters dendritic morphology in rat medial prefrontal cortex. Cereb Cortex 2005;15:1714-1722. [PubMed: 15703248]

Caspi A, Sugden K, Moffitt TE, Taylor A, Craig IW, Harrington H, McClay J, Mill J, Martin J, Braithwaite A, Poulton R. Influence of life stress on depression: moderation by a polymorphism in the 5-HTT gene. Science 2003;301:386-389. [PubMed: 12869766]

Cerqueira JJ, Mailliet F, Almeida OF, Jay TM, Sousa N. The prefrontal cortex as a key target of the maladaptive response to stress. J Neurosci 2007;27:2781-2787. [PubMed: 17360899]

Cerqueira JJ, Pego JM, Taipa R, Bessa JM, Almeida OF, Sousa N. Morphological correlates of corticosteroid-induced changes in prefrontal cortex-dependent behaviors. J Neurosci 2005;25:77927800. [PubMed: 16120780]

Cerqueira JJ, Taipa R, Uylings HB, Almeida OF, Sousa N. Specific configuration of dendritic degeneration in pyramidal neurons of the medial prefrontal cortex induced by differing corticosteroid regimens. Cereb Cortex. 2006 epub 2006 Nov 2.

Cook SC, Wellman CL. Chronic stress alters dendritic morphology in rat medial prefrontal cortex. J Neurobiol 2004;60:236-248. [PubMed: 15266654]

Corcoran C, Gallitano A, Leitman D, Malaspina D. The neurobiology of the stress cascade and its potential relevance for schizophrenia. J Psychiatr Pract 2001;7:3-14. [PubMed: 15990497]

Diorio D, Viau V, Meaney MJ. The role of the medial prefrontal cortex (cingulate gyrus) in the regulation of hypothalamic-pituitary-adrenal responses to stress. J Neurosci 1993;13:3839-3847. [PubMed: 8396170]

Figueiredo HF, Bruestle A, Bodie B, Dolgas CM, Herman JP. The medial prefrontal cortex differentially regulates stress-induced c-fos expression in the forebrain depending on type of stressor. Eur J Neurosci 2003;18:2357-2364. [PubMed: 14622198]

Grutzendler J, Kasthuri N, Gan WB. Long-term dendritic spine stability in the adult cortex. Nature 2002;420:812-816. [PubMed: 12490949]

Hao J, Rapp PR, Leffler AE, Leffler SR, Janssen WG, Lou W, McKay H, Roberts JA, Wearne SL, Hof $\mathrm{PR}$, Morrison JH. Estrogen alters spine number and morphology in prefrontal cortex of aged female rhesus monkeys. J Neurosci 2006;26:2571-2578. [PubMed: 16510735]

Harris KM, Stevens JK. Dendritic spines of CA 1 pyramidal cells in the rat hippocampus: serial electron microscopy with reference to their biophysical characteristics. J Neurosci 1989;9:2982-2997. [PubMed: 2769375]

Heim C, Owens MJ, Plotsky PM, Nemeroff CB. The role of early adverse life events in the etiology of depression and posttraumatic stress disorder. Focus on corticotropin-releasing factor. Ann N Y Acad Sci 1997;821:194-207. [PubMed: 9238204] 
Holtmaat AJ, Trachtenberg JT, Wilbrecht L, Shepherd GM, Zhang X, Knott GW, Svoboda K. Transient and persistent dendritic spines in the neocortex in vivo. Neuron 2005;45:279-291. [PubMed: 15664179]

Izquierdo A, Wellman CL, Holmes A. Brief uncontrollable stress causes dendritic retraction in infralimbic cortex and resistance to fear extinction in mice. J Neurosci 2006;26:5733-5738. [PubMed: 16723530]

Kasai H, Matsuzaki M, Noguchi J, Yasumatsu N, Nakahara H. Structure-stability-function relationships of dendritic spines. Trends Neurosci 2003;26:360-368. [PubMed: 12850432]

Kharazia VN, Weinberg RJ. Immunogold localization of AMPA and NMDA receptors in somatic sensory cortex of albino rat. J Comp Neurol 1999;412:292-302. [PubMed: 10441757]

Kirov SA, Petrak LJ, Fiala JC, Harris KM. Dendritic spines disappear with chilling but proliferate excessively upon rewarming of mature hippocampus. Neuroscience 2004;127:69-80. [PubMed: 15219670]

Knafo S, Libersat F, Barkai E. Olfactory learning-induced morphological modifications in single dendritic spines of young rats. Eur J Neurosci 2005;21:2217-2226. [PubMed: 15869518]

Krettek JE, Price JL. Projections from the amygdaloid complex to the cerebral cortex and thalamus in the rat and cat. J Comp Neurol 1977;172:687-722. [PubMed: 838895]

Liston C, Miller MM, Goldwater DS, Radley JJ, Rocher AB, Hof PR, Morrison JH, McEwen BS. Stressinduced alterations in prefrontal cortical dendritic morphology predict selective impairments in perceptual attentional set-shifting. J Neurosci 2006;26:7870-7874. [PubMed: 16870732]

Liu R, Aghajanian GK. Stress-related apical dendritic atrophy in layer V pyramidal cells of rat medial prefrontal cortex: association with deficits in serotonin and hypocretin/orexin excitatory responses. Soc Neurosci Abstr 2006;32:529.3.

Magariños AM, McEwen BS. Stress-induced atrophy of apical dendrites of hippocampal CA3c neurons: involvement of glucocorticoid secretion and excitatory amino acid receptors. Neuroscience 1995;69:89-98. [PubMed: 8637636]

Matsuzaki M, Honkura N, Ellis-Davies GC, Kasai H. Structural basis of long-term potentiation in single dendritic spines. Nature 2004;429:761-766. [PubMed: 15190253]

McEwen BS. Protective and damaging effects of stress mediators. N Engl J Med 1998;338:171-179. [PubMed: 9428819]

Murmu MS, Salomon S, Biala Y, Weinstock M, Braun K, Bock J. Changes of spine density and dendritic complexity in the prefrontal cortex in offspring of mothers exposed to stress during pregnancy. Eur J Neurosci 2006;24:1477-1487. [PubMed: 16965544]

Newport DJ, Nemeroff CB. Neurobiology of posttraumatic stress disorder. Curr Opin Neurobiol 2000;10:211-218. [PubMed: 10753802]

Nimchinsky EA, Sabatini BL, Svoboda K. Structure and function of dendritic spines. Annu Rev Physiol 2002;64:313-353. [PubMed: 11826272]

Nimchinsky EA, Yasuda R, Oertner TG, Svoboda K. The number of glutamate receptors opened by synaptic stimulation in single hippocampal spines. J Neurosci 2004;24:2054-2064. [PubMed: 14985448]

Nusser Z, Lujan R, Laube G, Roberts JD, Molnar E, Somogyi P. Cell type and pathway dependence of synaptic AMPA receptor number and variability in the hippocampus. Neuron 1998;21:545-559. [PubMed: 9768841]

Phillips LJ, Francey SM, Edwards J, McMurray N. Stress and psychosis: towards the development of new models of investigation. Clin Psychol Rev 2007;27:307-317. [PubMed: 17169470]

Racz B, Blanpied TA, Ehlers MD, Weinberg RJ. Lateral organization of endocytic machinery in dendritic spines. Nat Neurosci 2004;7:917-918. [PubMed: 15322548]

Radley JJ, Arias CM, Sawchenko PE. Regional differentiation of the medial prefrontal cortex in regulating adaptive responses to acute emotional stress. J Neurosci 2006a;26:12967-12976. [PubMed: 17167086]

Radley JJ, Rocher AB, Janssen WG, Hof PR, McEwen BS, Morrison JH. Reversibility of apical dendritic retraction in the rat medial prefrontal cortex following repeated stress. Exp Neurol 2005;196:199_ 203. [PubMed: 16095592] 
Radley JJ, Rocher AB, Miller M, Janssen WG, Liston C, Hof PR, McEwen BS, Morrison JH. Repeated stress induces dendritic spine loss in the rat medial prefrontal cortex. Cereb Cortex 2006b;16:313320. [PubMed: 15901656]

Radley JJ, Rocher AB, Rodriguez A, Ehlenberger D, McEwen BS, Morrison JH, Wearne SL, Hof PR. Repeated stress induces dendritic spine morphologic alterations in the rat medial prefrontal cortex. Soc Neurosci Abstr 2006c;32:370.5.

Radley JJ, Sisti HM, Hao J, Rocher AB, McCall T, Hof PR, McEwen BS, Morrison JH. Chronic behavioral stress induces apical dendritic reorganization in pyramidal neurons of the medial prefrontal cortex. Neuroscience 2004;125:1-6. [PubMed: 15051139]

Rodriguez A, Ehlenberger D, Kelliher K, Einstein M, Henderson SC, Morrison JH, Hof PR, Wearne SL. Automated reconstruction of three-dimensional neuronal morphology from laser scanning microscopy images. Methods 2003;30:94-105. [PubMed: 12695107]

Rodriguez A, Ehlenberger DB, Hof PR, Wearne SL. Rayburst sampling, an algorithm for automated three-dimensional shape analysis from laser scanning microscopy images. Nat Protoc 2006;1:21522161. [PubMed: 17487207]

Sapolsky RM. Why stress is bad for your brain. Science 1996;273:749-750. [PubMed: 8701325]

Shin LM, Orr SP, Carson MA, Rauch SL, Macklin ML, Lasko NB, Peters PM, Metzger LJ, Dougherty DD, Cannistraro PA, Alpert NM, Fischman AJ, Pitman RK. Regional cerebral blood flow in the amygdala and medial prefrontal cortex during traumatic imagery in male and female Vietnam veterans with PTSD. Arch Gen Psychiatry 2004;61:168-176. [PubMed: 14757593]

Shin LM, Whalen PJ, Pitman RK, Bush G, Macklin ML, Lasko NB, Orr SP, McInerney SC, Rauch SL. An fMRI study of anterior cingulate function in posttraumatic stress disorder. Biol Psychiatry 2001;50:932-942. [PubMed: 11750889]

Swanson, LW. Brain Maps: Structure of the Rat Brain. New York: Elsevier; 1992.

Takumi Y, Ramirez-Leon V, Laake P, Rinvik E, Ottersen OP. Different modes of expression of AMPA and NMDA receptors in hippocampal synapses. Nat Neurosci 1999;2:618-624. [PubMed: 10409387]

Trachtenberg JT, Chen BE, Knott GW, Feng G, Sanes JR, Welker E, Svoboda K. Long-term in vivo imaging of experience-dependent synaptic plasticity in adult cortex. Nature 2002;420:788-794. [PubMed: 12490942]

Vogt BA, Peters A. Form and distribution of neurons in rat cingulate cortex: areas 32, 24, and 29. J Comp Neurol 1981;195:603-625. [PubMed: 7462444]

Watanabe Y, Gould E, McEwen BS. Stress induces atrophy of apical dendrites of hippocampal CA3 pyramidal neurons. Brain Res 1992;588:341-345. [PubMed: 1393587]

Wearne SL, Rodriguez A, Ehlenberger DB, Rocher AB, Henderson SC, Hof PR. New techniques for imaging, digitization and analysis of three-dimensional neural morphology on multiple scales. Neuroscience 2005;136:661-680. [PubMed: 16344143]

Wellman CL. Dendritic reorganization in pyramidal neurons in medial prefrontal cortex after chronic corticosterone administration. J Neurobiol 2001;49:245-253. [PubMed: 11745662]

Woolley CS, McEwen BS. Estradiol regulates hippocampal dendritic spine density via an N-methyl-Daspartate receptor-dependent mechanism. J Neurosci 1994;14:7680-7687. [PubMed: 7996203]

Yuste R, Bonhoeffer T. Genesis of dendritic spines: insights from ultrastructural and imaging studies. Nat Rev Neurosci 2004;5:24-34. [PubMed: 14708001]

Zhang S, Boyd J, Delaney K, Murphy TH. Rapid reversible changes in dendritic spine structure in vivo gated by the degree of ischemia. J Neurosci 2005;25:5333-5338. [PubMed: 15930381] 

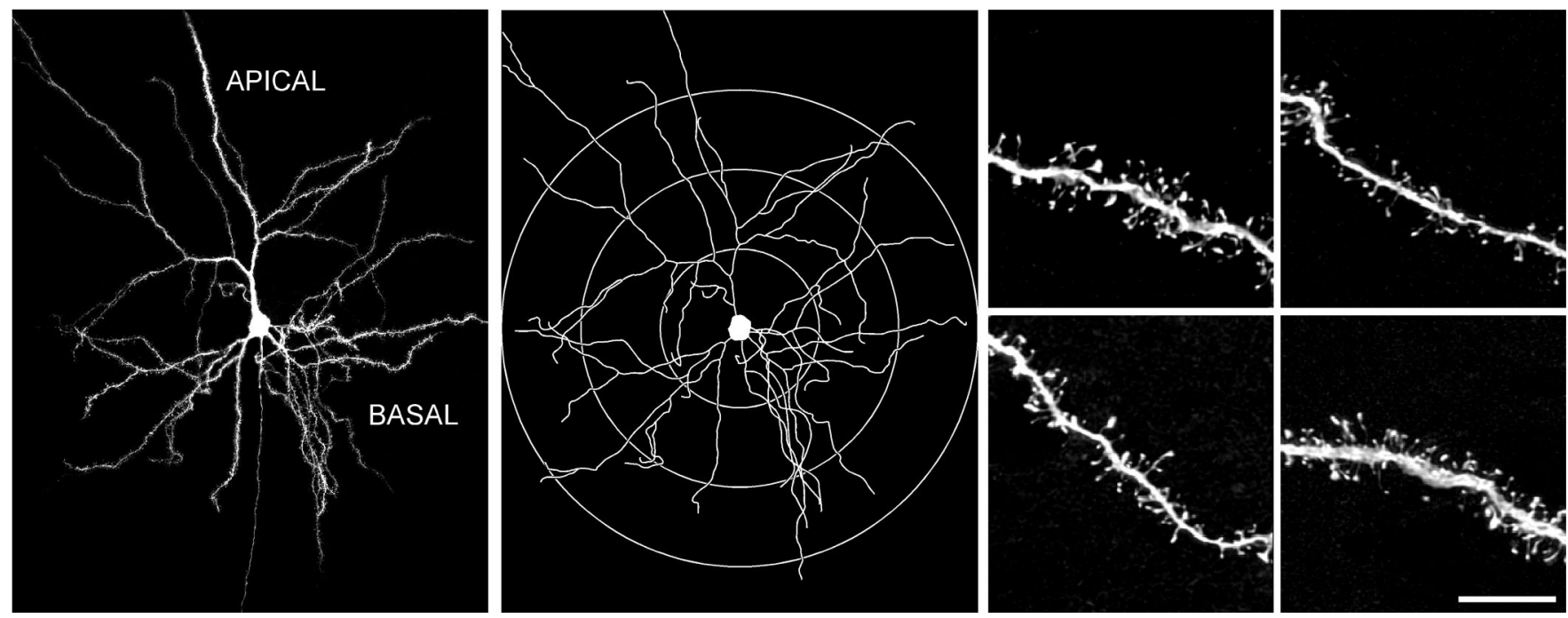

Figure 1. Methodology for comprehensive spine morphologic analysis of pyramidal neurons in layers II/III of dorsal mPFC

Left: Digital reconstruction of a Lucifer Yellow-filled neuron in the rat dorsal mPFC at 160x magnification on a Zeiss 410 laser-scanning microscope from 5 separate confocal digital stacks $(z$-step $=0.5 \mu \mathrm{m})$, that were deconvolved and aligned in the $x-y-z$ planes using Vias software (Rodriguez et al., 2003; Radley et al., 2006b). Middle: 2-dimensional map for the same neuron reconstructed with Neurolucida (MBF Biosciences). The different colored branches indicate increasing branch orders within single dendritic arbors. Radial distances are shown to depict the different zones within which segments were selected for dendritic reconstructions $(<75$ $\mu \mathrm{m}, 75-150 \mu \mathrm{m},>150 \mu \mathrm{m})$ at high magnification. Right: Examples of dendritic segments, imaged at 5,000X magnification $(z$-step $=0.1 \mu \mathrm{m})$. Scale bar $=150 \mu \mathrm{m}($ left $) ; 10 \mu \mathrm{m}($ right $)$. 

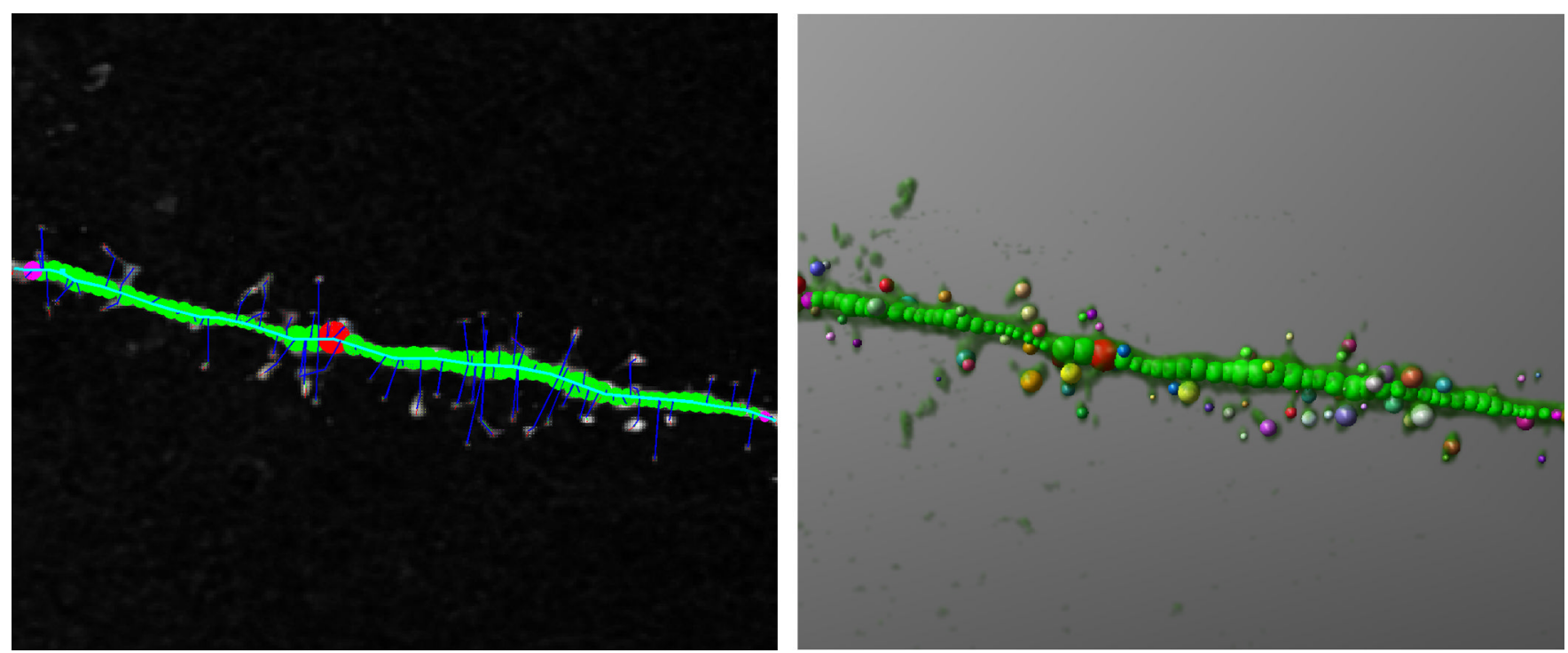

Figure 2. Analysis of spine morphometric parameters with the Rayburst-based automated spine analysis system

The Rayburst-based approach was used for the calculation of spine morphological parameters (Wearne et al., 2005; Rodriguez et al., 2006), involving 3D reconstruction and geometric analysis on deconvolved optical stacks of dendritic segments in two principal steps. First, the medial axis of the dendritic segment is extracted using a dynamically adjusting local segmentation technique (left). Next, a Rayburst Sampling algorithm extracts dendrite and spine geometric features (right), yielding spine volume, length, and surface area for each spine on the segment, for all angles of orientation. 



Figure 3. Anatomical localization of Lucifer Yellow-filled layers II/III pyramidal neurons in mPFC for subregional analysis

Atlas plates (modified from Swanson, 1992) of coronal sections through a similar level of the $\mathrm{mPFC}$ from animals that received intracellular Lucifer Yellow injections. Neurons from layers II/III in the dorsal mPFC were identified using a fluorescent nucleic acid stain, followed by iontophoretic injections with Lucifer Yellow. The location for each filled neuron is designated for each treatment with a triangle (control, blue; stress, red). ACd, anterior cingulate cortex, dorsal subdivision; ACv anterior cingulate cortex, ventral subdivision; PL, prelimbic area; IL, infralimbic area. 

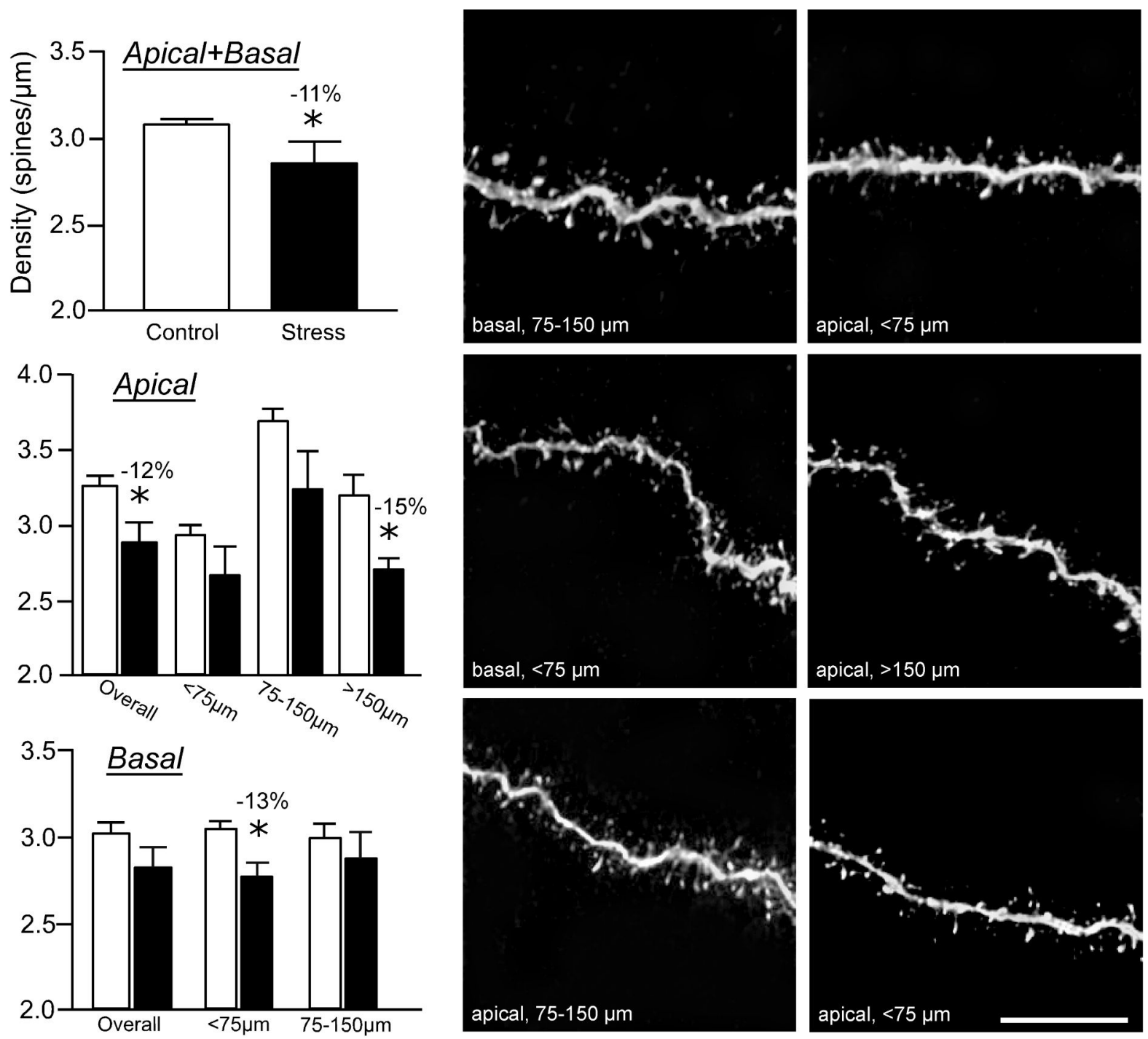

Figure 4. Repeated restraint stress reduces dendritic spine density in layer II/III pyramidal neurons Repeated restraint stress ( 21 days, 6 hours/day) induces decreases in overall (upper left) and apical dendritic spine density (middle left). This effect is most prominent in more distal portions $(>150 \mu \mathrm{m})$ of apical dendrites. While there was no overall effect of stress on basal dendrites, a significant reduction of spine density was present at $<75 \mu \mathrm{m}$ from the soma (lower left). The spine density values for each dendritic segment were quantified using the Rayburst-based automated approach and was similar to previous estimates that involved manually counting spines from optical stacks by controlling the plane of focus for $z$-step increments and marking spines as they appear on the dendritic segment (Radley et al., 2006b). Examples of dendritic segments are shown in the middle (control) and right (21 days stress) columns. *, differs significantly from unstressed controls; $P<0.05$. Scale bar $=10 \mu \mathrm{m}$. 


\section{Apical+Basal:}

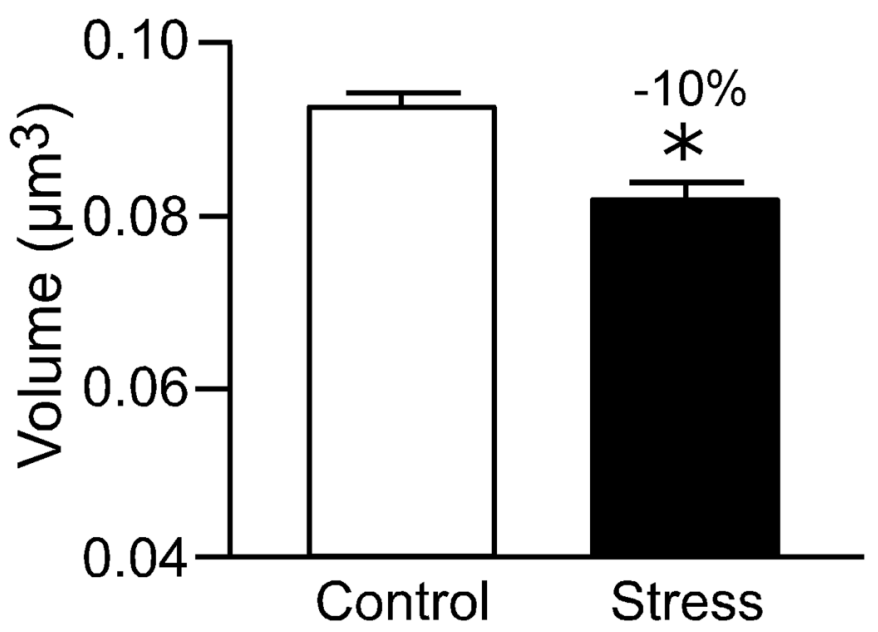

Apical/Basal:

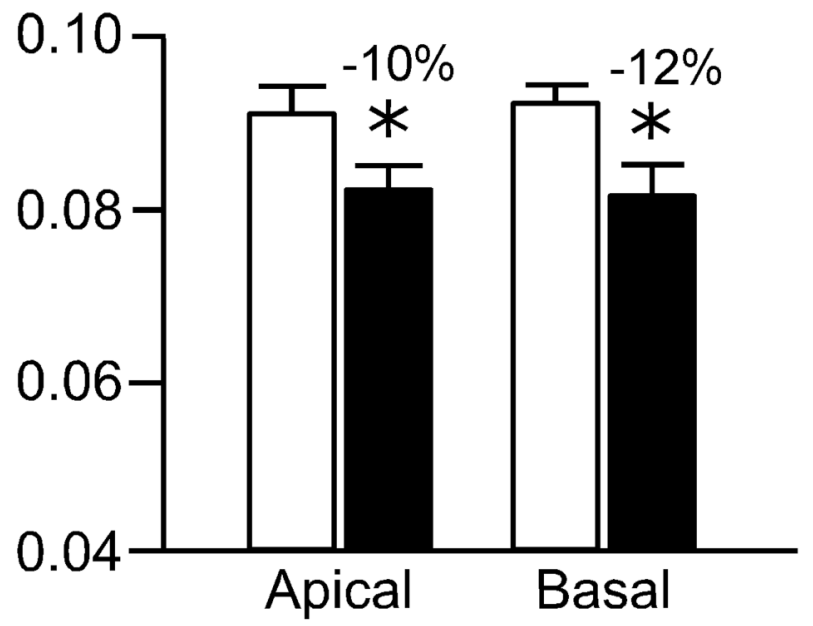

Apical:

Basal:
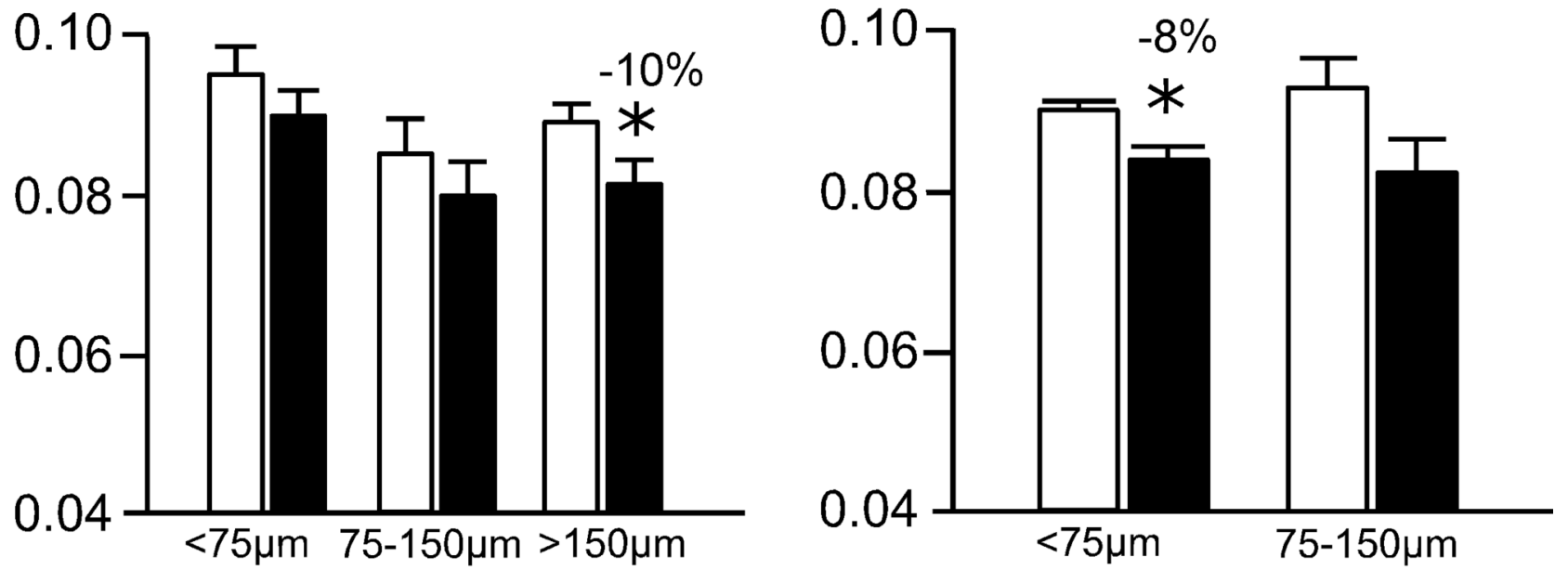

Figure 5. Effects of repeated restraint stress on Rayburst volumes of dendritic spines in layers II/ III pyramidal neurons in the dorsal mPFC

Values from individual spines on each dendritic segment were averaged, and then averaged for each animal ( $\mathrm{N}=5$ neurons/animal), and values per animal were used for comparison of means $(\mathrm{N}=5$ /group $)$. Values represent mean + SEM. $*, P<0.05$. 

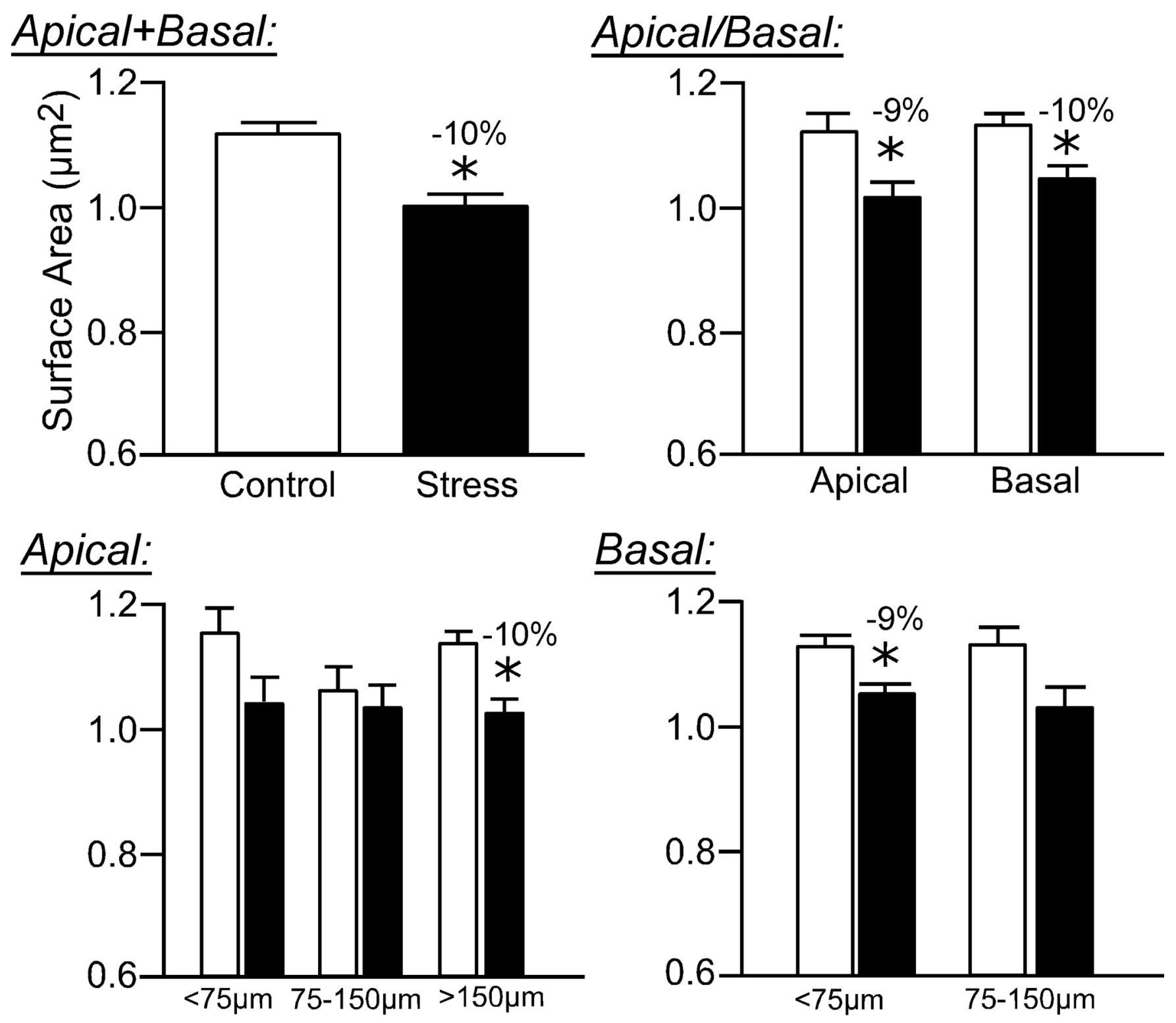

Basal:

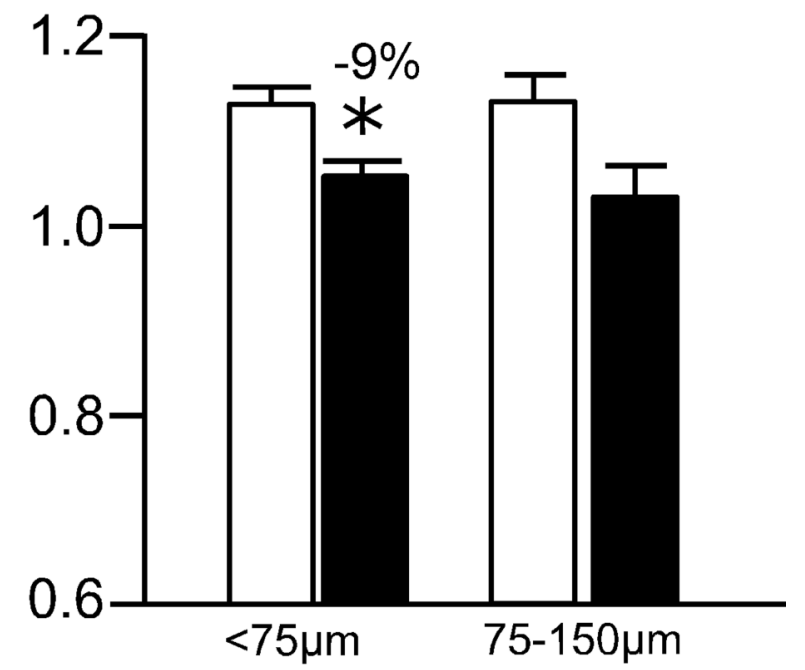

Figure 6. Effects of repeated restraint stress on Rayburst surface areas of dendritic spines in layers II/III pyramidal neurons in the dorsal mPFC

Values from individual spines on each dendritic segment were averaged, and then averaged for each animal ( $\mathrm{N}=5$ neurons/animal), and values per animal were used for comparison of means $(\mathrm{N}=5$ /group). Values represent mean + SEM. $*, P<0.05$. 

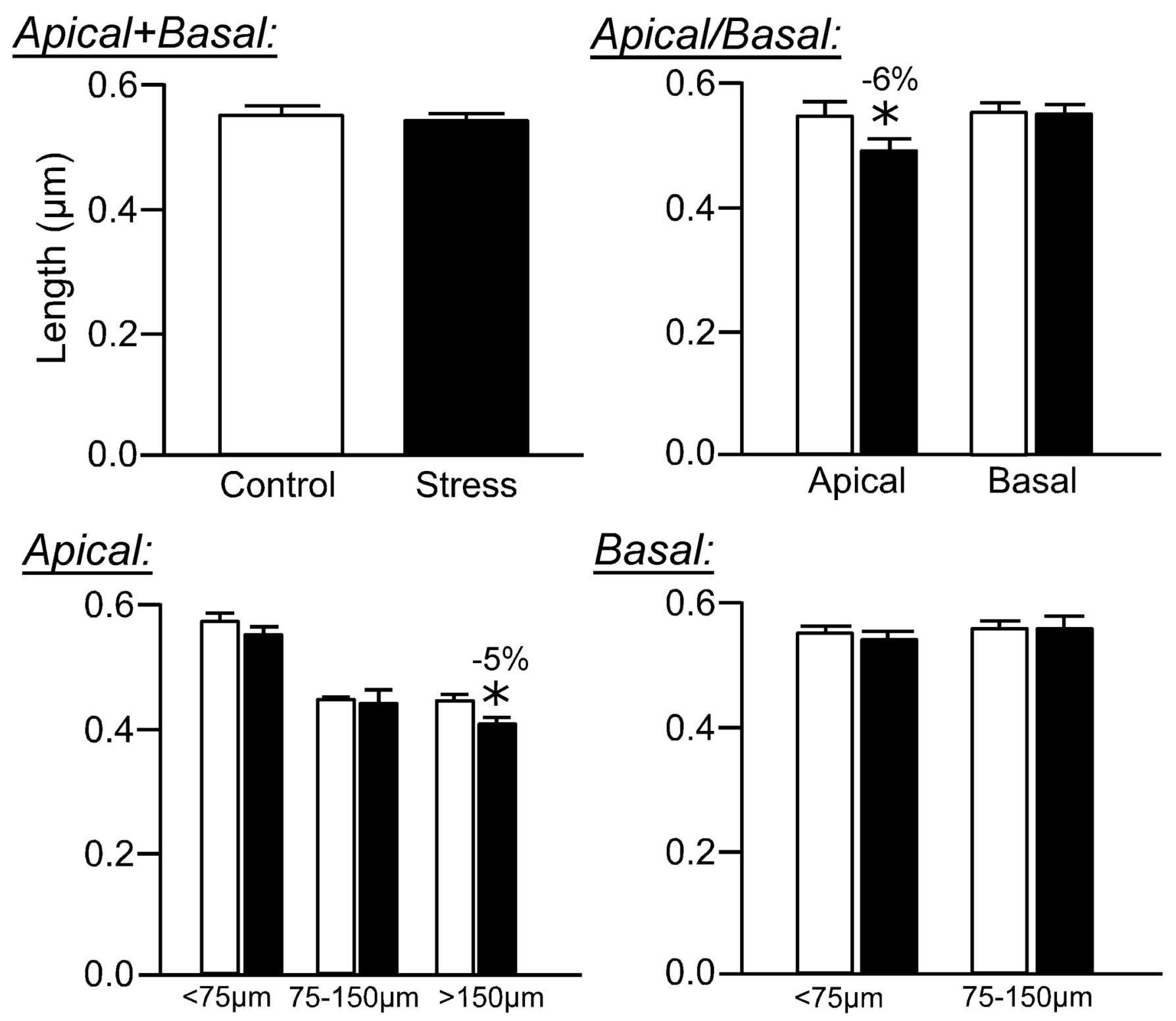

Figure 7. Effects of repeated restraint stress on dendritic spine lengths in layers II/III pyramidal neurons in the dorsal mPFC

Values from individual spines on each dendritic segment were averaged, and then averaged for each animal $(\mathrm{N}=5$ neurons/animal), and values per animal were used for comparison of means $(\mathrm{N}=5$ /group). Values represent mean $+\mathrm{SEM}$. $*, P<0.05$. 

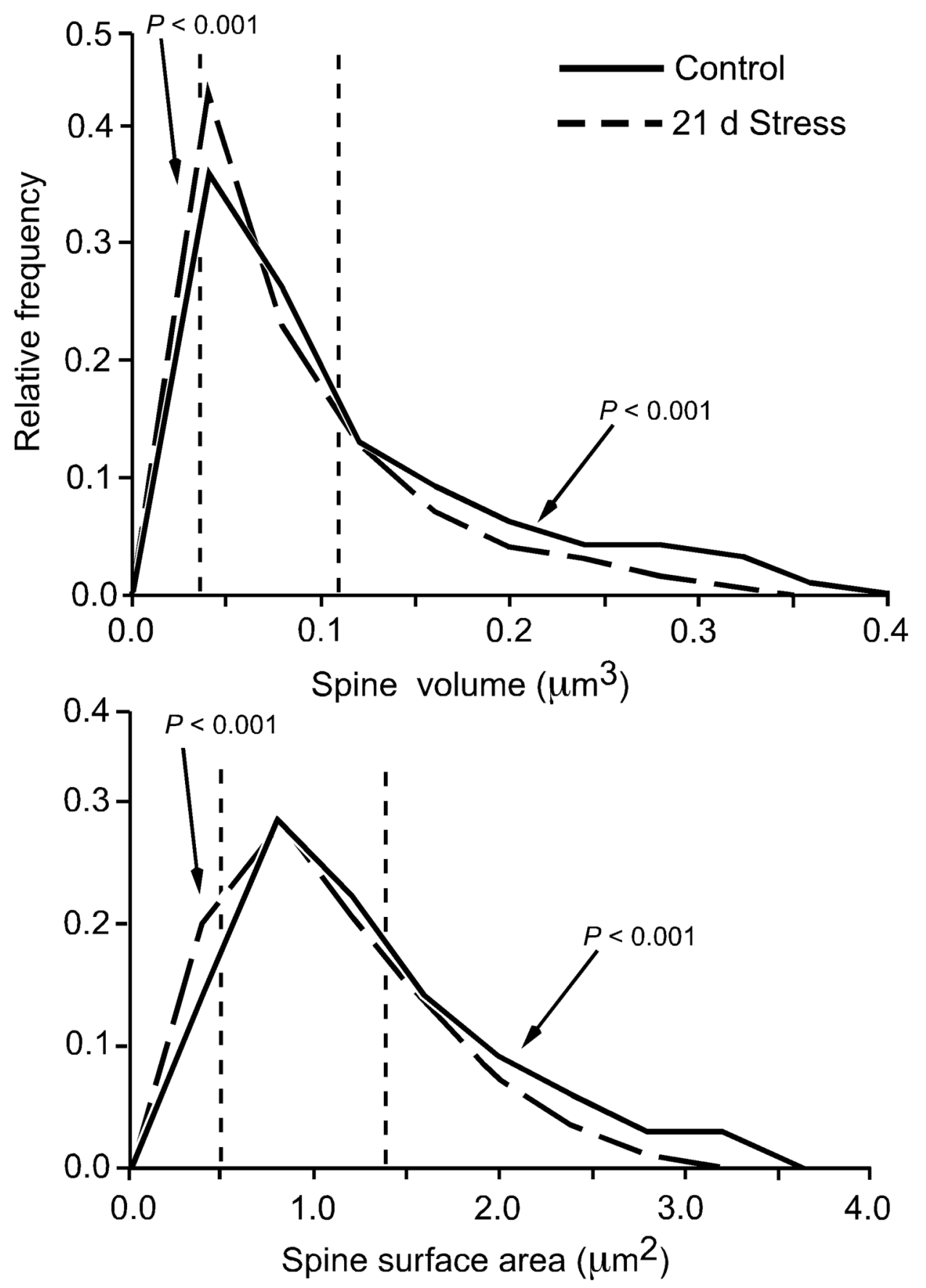

Figure 8. Probability distributions for spine volume and surface area for distal apical dendritic segments

The distributions were derived from high-resolution imaging of spines on apical dendritic segments at radial distances greater than $150 \mu \mathrm{m}$ relative to the soma, and analyzed using the Rayburst-based automated approach (Control = 1,629 spines; 21 days stress $=1,438$ spines). The dashed vertical lines in each histogram shows the 25 th and 75 th percentiles of the entire spine population (i.e., 3,067 spines). These frequency distributions illustrate how repeated stress results in an overall downward shift in spine morphometric parameters. 


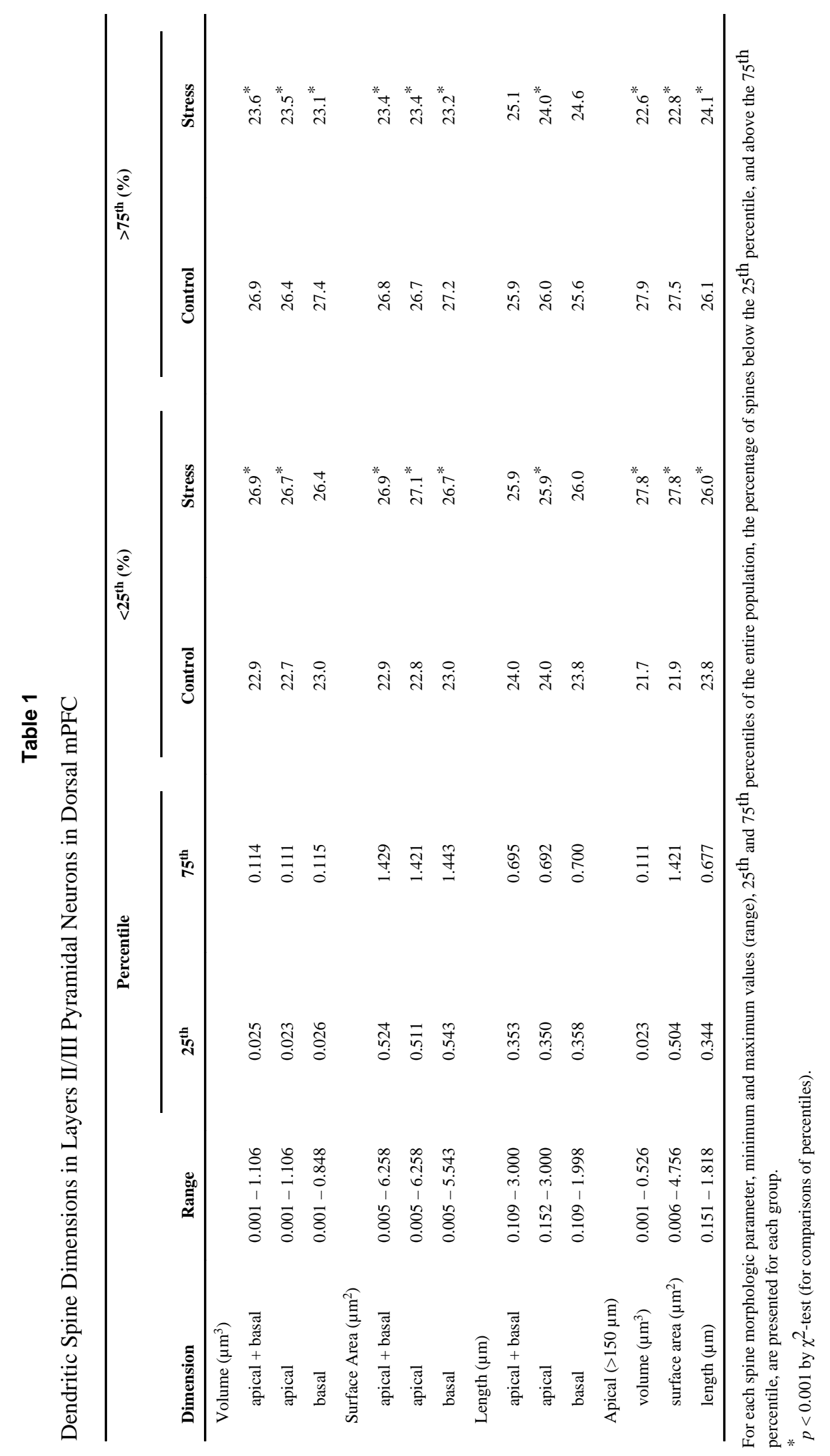

J Comp Neurol. Author manuscript; available in PMC 2009 December 21. 